\title{
Sugarcane Bagasse as the Source of Nanocrystalline Cellulose for Gelatin-Free Capsule Shell
}

\author{
Zakir Sabara ${ }^{D},{ }^{1}$ Alfirah Mutmainnah, ${ }^{1}$ Ummu Kalsum, ${ }^{1}$ Irma Nur Afiah, ${ }^{1}$ Ismalia Husna, ${ }^{2}$ \\ Antomi Saregar $\mathbb{D}^{3},{ }^{3}$ Irzaman $\left(\mathbb{D},{ }^{4}\right.$ and Rofiqul Umam ${ }^{5}{ }^{5}$ \\ ${ }^{1}$ Faculty of Industrial Technology, Universitas Muslim Indonesia, Makassar, Indonesia \\ ${ }^{2}$ Department of Parasitology, Faculty of Medicine, Universitas Malahayati, Bandar Lampung, Indonesia \\ ${ }^{3}$ Department of Physics Education, UIN Raden Intan Lampung, Bandar Lampung, Indonesia \\ ${ }^{4}$ Department of Physics, Bogor Agricultural University, Bogor, Indonesia \\ ${ }^{5}$ Department of Applied Chemistry for Environment, Kwansei Gakuin University, Sanda, Japan \\ Correspondence should be addressed to Zakir Sabara; zakir.sabara@umi.ac.id
}

Received 21 December 2021; Revised 23 January 2022; Accepted 28 January 2022; Published 14 February 2022

Academic Editor: Swarup Roy

Copyright (c) 2022 Zakir Sabara et al. This is an open access article distributed under the Creative Commons Attribution License, which permits unrestricted use, distribution, and reproduction in any medium, provided the original work is properly cited.

\begin{abstract}
Gelatin-free capsules are possibly produced through an innovation which involves utilizing environmentally friendly materials derived from plants such as bagasse which are produced into nanocrystalline cellulose (NCC). This research was conducted to report the extraction and characterization of NCC from the abundant industrial plantation waste of sugarcane and its application as the base material for gelatin-free capsule shell material. The process involved using different concentrations of NCC at $1 \%, 2 \%$, $4 \%$, and $7 \%$ (in wt. \%) with the addition of 1\% hydroxypropyl methylcellulose (HPMC) (in wt. \%) and 1\% carbopol (in wt. \%). Moreover, the NCC capsules obtained from sugarcane bagasse were tested for moisture content, tensile strength, elongation, solubility, and $\mathrm{pH}$. The results showed that sugarcane bagasse contains $40-50 \%$ cellulose, $6.15 \%-9.5 \%$ moisture content which indicates they are potentially better in terms of storage, $7.25-7.85 \mathrm{pH}$, and $0.05-0.136 \mathrm{MPa}$ gel strength, and the elongation value ranges from 7.19 to $87.51 \%$. These values were discovered to have satisfied the standard requirements as indicated by the optimal concentration of $4 \%$ NCC $+1 \%$ HPMC, which is in line with the Japanese Industrial Standard (JIS), thereby leading to the consideration of the material safe to be used as raw material in making capsule shells.
\end{abstract}

\section{Introduction}

Indonesia is a country with a tropical climate which allows different types of plants such as sugarcane (Saccharum officinarum L.) to thrive. This plant is normally used as the raw material to produce sugar to meet the needs of the community. It is important to note that the production process usually has $90 \%$ bagasse, $5 \%$ molasses, and $5 \%$ water with the bagasse reported to be used only as a fuel for sugarcane processing [1]. Meanwhile, the ash from the uncontrolled burning of bagasse has been proven to be causing serious air pollution problems [2], thereby [3] making it necessary to find better environmentally friendly alternatives [4]. This led to the selection of sugarcane as the raw material to be used in producing nanocrystalline cellulose (NCC) for gelatin-free capsule shell material due to its several advantages such as the $40-50 \%$ cellulose content [5] and availability in large quantities.

Capsules are one of the pharmaceutical dosage forms normally used to package drugs in powder form to cover the taste and smell considered by some people to be irritating, thereby making the treatment process easier [6]. It was reported that several types of capsules especially those containing gelatin usually have the problem of stability [7]. This is associated with the fact that gelatin is one of the ingredients in animal protein mostly obtained from the bones and skins of livestock such as cows and pigs from slaughterhouses by capsule manufacturing factories [8]. It is also important to note that gelatin has also been applied in the food industry in addition to medicine and 
pharmaceuticals due to its ability to form hydrogels in the $\mathrm{pH}$ range without the aid of ionic or other additives [9]. However, gelatin capsules cannot be used for drugs and highly hygroscopic drugs due to the fact they also have high moisture content and need to be stored at $45-60 \%$ humidity. They also have the ability to experience cross-linking which can make their shell very hard [10]. These shortcomings led to the production of capsules from nongelatin materials [7].

Capsule shells have been manufactured using hydroxypropyl methylcellulose (HPMC) [11] which has better physical stability when compared to gelatin. This HPMC, however, has a lower tensile strength value due to the lack of NCC, and this normally causes problems during the capsule shell manufacturing process [12].

This study was used to manufacture capsule shells using bagasse as the raw material for the NCC while HPMC and carbopol were used as the base formula for the mixture. Carbopol is a fine white, acidic, and hygroscopic powder selected due to its ability to easily disperse in water and function as a gel base with sufficient viscosity in small concentrations, thereby leading to small dispersion and long adhesion. The main goal of this study is to produce gelatinfree capsule shells with a higher tensile strength value than those produced in previous studies [13]. It was also focused on measuring certain parameters such as moisture content, solubility, $\mathrm{pH}$, and disintegration time as well as mechanical strength such as tensile strength and elongation to determine their conformity with the Japanese Industrial Standard (JIS) [14].

\section{Materials and Methods}

2.1. Sugarcane Waste Materials and Preparation. The bagasse used as the raw material was obtained from the industrial waste of sugar cane plantations in Takalar Regency, South Sulawesi, Indonesia. In the process, the bagasse is washed first to remove impurities such as soil and others. Furthermore, the process of drying the bagasse is carried out using sunlight for 1-2 days depending on the weather. After the drying process is complete, the bagasse is then cut and ground using a milling machine (FOMAC FCT-Z500) to form a powder. Based on the information obtained from the performance specifications of the milling machine (FOMAC FCT-Z500), it can produce powders with a fineness level reaching 20-180 mesh with an engine rotation speed of $2800 \mathrm{rpm}$. These processes were conducted between July and September 2021 at the Chemical Engineering Research Laboratory, Faculty of Industrial Technology, Indonesian Muslim University, Makassar, South Sulawesi, Indonesia.

2.2. Cellulose Extraction (CE). A total of 50 grams of bagasse powder was hydrolyzed using $400 \mathrm{ml}$ of $3.5 \% \mathrm{HNO}_{3}$ and heated at $90^{\circ} \mathrm{C}$ for 2 hours. After that, it was washed, filtered, bleached with $3.5 \% \mathrm{NaOCl}$, and boiled for 10 minutes before it was finally washed and filtered again. This was followed by the $\mathrm{CE}$ which involved adding $\mathrm{NaOH}$ to $17.5 \%$ of the total bagasse powder and heating at a temperature of $80{ }^{\circ} \mathrm{C}$ for 30 minutes, and then, the washing and filtering processes were conducted again, followed by bleaching with a $3.5 \% \mathrm{NaOCl}$ solution at a temperature of $100^{\circ} \mathrm{C}$ for 10 minutes [15]. The final result of this bleaching process was washed up to the moment the $\mathrm{pH}$ became neutral and later dried in an oven at $60^{\circ} \mathrm{C}$ to obtain alpha-cellulose which was characterized using FTIR (Fourier-transform infrared spectroscopy) to analyze its functional groups.

Although the bagasse has been processed to form a powder, in the next process, which is hydrolysis, it is necessary to add $500 \mathrm{ml}$ of $50 \%$ sulfuric acid until the hydrolysis process is stopped by adding distilled water so that the final sample obtained is in liquid form. The IR spectrometry technique used in this study was transmittance by adding $\mathrm{KBr}$ as a crystalline. The transmission method is one of the techniques for measuring absorption/molecular vibration with an FTIR. The sample is subjected to a direct laser beam to determine the vibrational pattern of the molecule. In this method, solid samples are made in the form of clear pellets with the help of $\mathrm{KBr}$. The $\mathrm{KBr}$ sample pellets were then analyzed using an FTIR. The measurements were made in the range of wavenumbers from 4000 to $400 \mathrm{~cm}^{-1}$.

\subsection{Nanocrystalline Cellulose (NCC) Synthesis.} Nanocrystalline cellulose (NCC) was prepared by acid hydrolysis using sulfuric acid solution with $50 \%$ concentration used to hydrolyze sugarcane bagasse cellulose for 30 minutes at $45^{\circ} \mathrm{C}$. It is important to note that cellulose fibers degrade [16]when they are reacted with acids, and this was observed to have started at the region of the weakest bond which is the amorphous or noncrystalline region, as indicated in Figure 1. The reduced amorphous region caused the crystallinity of cellulose to increase, thereby leading to nanocrystalline cellulose or interfibrillar molecules.

The sugarcane bagasse powder dried through cellulose extraction was also hydrolyzed with $500 \mathrm{ml}$ of $50 \%$ sulfuric acid at $45^{\circ} \mathrm{C}$ for 30 minutes, and the process was stopped by adding distilled water to the reaction mixture. The colloid produced was centrifuged and later dialyzed with distilled water to have a $\mathrm{pH}$ of 6. From this process, NNC was obtained and characterized again through FTIR to determine its functional group.

2.4. Capsule Casting. The gel was produced by dissolving NCC at $1 \%, 2 \%, 4 \%$, and $7 \%$ (in wt. \%) and then the mixing process was conducted with the addition of 1\% HPMC (in wt. \%) and $1 \%$ carbopol (in wt. \%) each into distilled water at a temperature of $30^{\circ} \mathrm{C}$ for 30 minutes and a speed of $500 \mathrm{rpm}$. The gel formed was printed with a capsule printer, and the gel film attached to the capsule printer was dried in an oven at $60^{\circ} \mathrm{C}$ for 3 hours, and then, the capsule was removed from the mold and its properties including moisture content, tensile strength, elongation, solubility, $\mathrm{pH}$, and the time evaluation of capsule shell rupture were analyzed.

On the other hand, PEG-400 and glycerin are added to the capsule shell formulation as plasticizers. The addition of a plasticizer reduces the stiffness of the polymer and increases the flexibility of the resulting capsule shell [17]. PEG400 was chosen in the formulation because it can absorb 


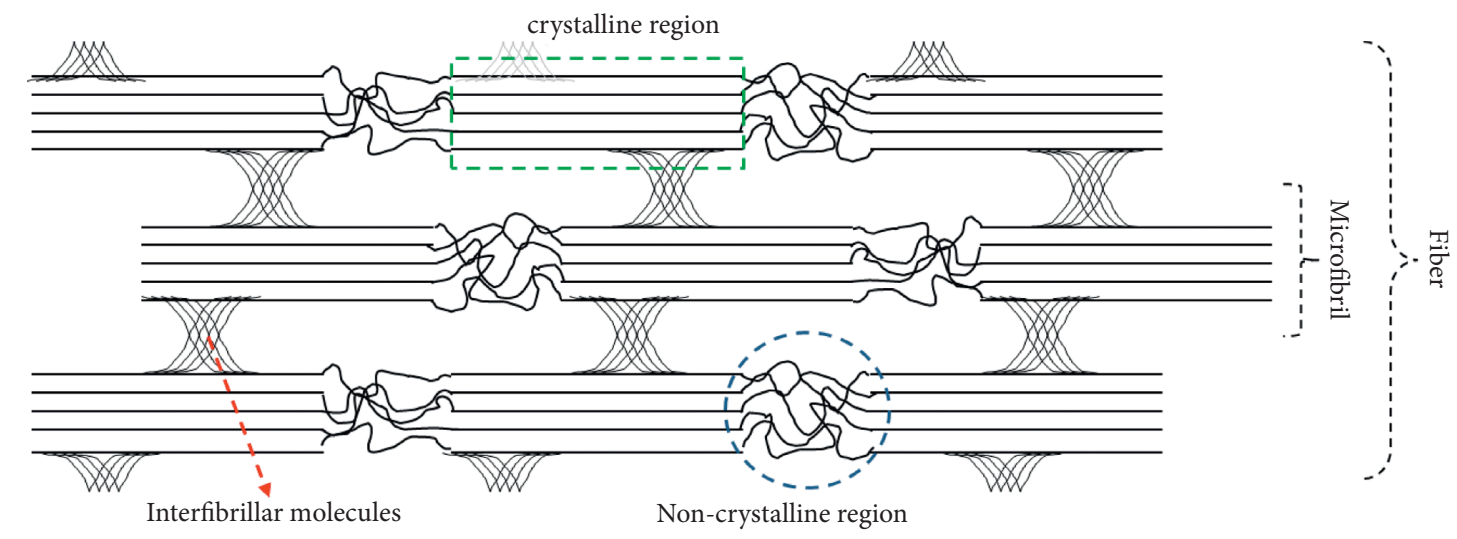

FIgURE 1: The crystalline and amorphous structures of cellulose. The red dotted arrow is the degradation of the amorphous or noncrystalline region with the weakest bond, this location being the site of the production of nanocrystalline cellulose or interfibrillar molecules.

moisture from the capsule shell. The concentration of PEG400 used was $2 \%$.

2.5. Disintegration Test. The disintegration time test used a tool known as the disintegration test. In its application, the disintegration time of the capsule shell is very important to estimate when the drug in the capsule will start to work on the human body [18]. The process of testing the disintegration time was carried out by inserting 1 capsule and water at $37^{\circ} \mathrm{C}$ into each glass tube. The glass tube containing the capsule is then placed into the basket of the disintegration tester machine [19]. After the engine is started, the basket moves up and down in the transparent solution at a speed of 29-32 rpm. The disintegration time interval is 5-15 minutes. The capsules within the time limit stated in each monograph were observed until the capsule shell disintegrates or dissolves in water [20].

\section{Results and Discussion}

3.1. Proximate and Ultimate Analyses of the Sugarcane Bagasse. The proximate and ultimate analyses were conducted to determine the quality of the starting material which is the sugarcane bagasse used for the extraction of cellulose and NCC. The moisture content, hydrogen, oxygen, and ash of the raw materials were observed to have a significant effect on the properties of the NCC produced [17] as indicated in the proximate results presented in Table 1. It was discovered that the composition of the bagasse produced is quite different from the previous report provided by Adebisi et al. [1] due to the use of different sugarcane species, as reported to have used Saccharum officinarum which originates from Nigeria, Africa.

The sugarcane bagasse used in this study had an ash content value of $2.5 \%$, and this is considered to be a good quality raw material to manufacture soft capsule shells due to the fact that it is more than $0.5 \%$. However, the hydrogen and oxygen contents were fairly high at $6.5 \%$ and $44 \%$, respectively, thereby affecting the dispersion properties in water [21]. This led to the addition of a mixture of HPMC and carbopol to improve the quality of the capsule shell produced to ensure that it is easily dispersed in water and also produced in small concentrations to serve as a gel base with sufficient viscosity to increase the adhesion [11].

3.2. Analysis of Cellulose Extraction (CE) and Synthesis of Nanocrystalline Cellulose (NCC). Bagasse prepared into powder before the CE and NCC processes was analyzed using FTIR to determine its functional groups or contents such as cellulose, hemicellulose, lignin, minerals, wax, and other components [1]which have the ability to affect its properties and characteristics as a base material for capsule shells. The results of the CE and NCC characterization analysis are shown in Figures 2 and 3 and described in Table 2.

The FTIR spectra for the CE and NCC presented in Figures 2 and 3 showed there is a band part of the CE not found in the NCC while a difference was observed in the $896.93 \mathrm{~cm}^{-1}$ recorded in Figures 2 and $1,157.33 \mathrm{~cm}^{-1}$ in Figure 3. Moreover, the FTIR characterization showed there were changes after the bagasse had been processed into cellulose and nanocrystalline cellulose, while several bands were observed to be shared by all samples (CE and NCC) analyzed, as shown in the areas of $3,443.05 \mathrm{~cm}^{-1}$ and $3,433.41 \mathrm{~cm}^{-1}$ which indicate the moisture content of the $\mathrm{O}-\mathrm{H}$ stretching vibration as well as areas of $2,920.32 \mathrm{~cm}^{-1}$ and $2,860.53 \mathrm{~cm}^{-1}$ which show the presence of carbon and hydrogen bonds in Sp3 C-H stretching [22]. Furthermore, the peaks in the area of $1,371.43 \mathrm{~cm}^{-1}$ and $1,403.30 \mathrm{~cm}^{-1}$ indicate the presence of cellulose and lignin in the $\mathrm{C}-\mathrm{O}$ or $\mathrm{C}-\mathrm{H}$ bonds, while those of $1,643.41 \mathrm{~cm}^{-1}$ and $1,635.69 \mathrm{~cm}^{-1}$ show that water was absorbed by cellulose. All these results are presented in Table 2 .

3.3. Physicochemical Properties of Cellulose Extraction (CE) and Synthesis of Nanocrystalline Cellulose (NCC). The physicochemical properties of sugarcane bagasse presented in Table 3 showed that the cellulose extracted ranged between 40 and $50 \%$. It is important to note that the cellulose content can be influenced by several factors such as the type of sugarcane, the bleaching process [23], and the extraction temperature [24]. This is indicated by the fact that the yield 
TABLe 1: Proximate and ultimate analyses of sugarcane bagasse waste materials.

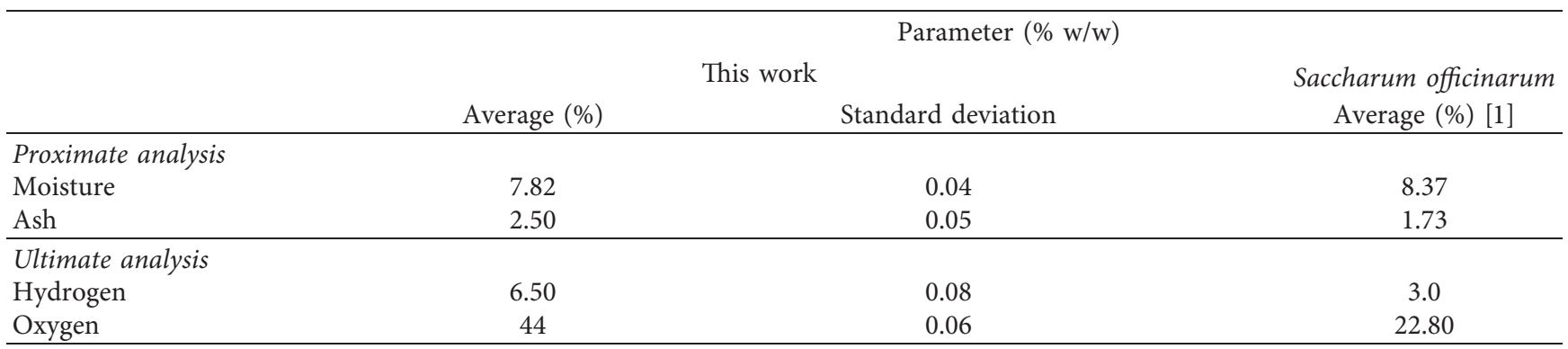

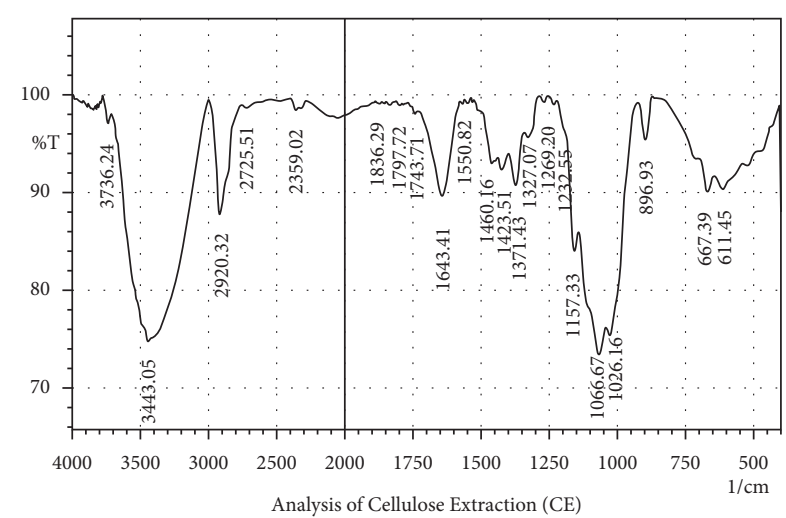

Figure 2: The results of the analysis of cellulose extraction (CE) using FTIR.

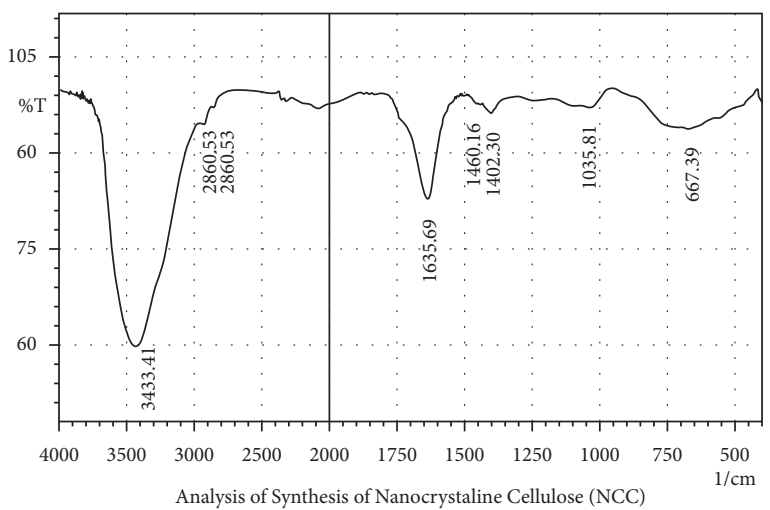

FIGURE 3: The results of the analysis of nanocrystalline cellulose (NCC) using FTIR.

produced in this study was higher than those from previous studies and other types of plants [1]. Furthermore, the degradation and hydrolysis processes were conducted to synthesize nanocrystalline cellulose (NCC) as the basic material to produce capsule shells at different concentrations at $1 \%, 2 \%, 4 \%$, and $7 \%$, with the addition of hydroxypropyl methylcellulose (HPMC) and carbopol.

$\mathrm{pH}$ is an important factor to determine the quality of nanocrystalline cellulose (NCC) and ensure it is safe to use as a raw material. It was discovered that the $\mathrm{pH}$ values of the NCC ranged from 7.25 to 7.85 , as shown in Figure 4, and this means it complies with the Japanese Industrial Standard (JIS) for capsule shells, which are estimated at 6.5-8.5. This further showed that the material is safe to be used as raw material to produce capsule shells [25].

Gel strength is the most important physical property of NCC due to its ability to describe the strength of intermolecular cohesion [12] and proportionality to its molecular weight [11]. The results presented in Tables 3 and 4 and Figure 5 showed that NCC 7\% with HPMC has the highest gel strength of $0.1361 \mathrm{MPa}$, while NCC $2 \%$ with HPMC has the lowest gel strength of $0.0765 \mathrm{MPa}$. These values were observed not to be in line with the Japanese Industrial Standard (JIS) [26], which requires a minimum of $0.3 \mathrm{MPa}$ for NCC. In a previous study, Nurilmala et al. explained that gel strength was influenced by the presence of gelatin and was determined by the viscosity value of each gelatin [27]. In this study, the low value of gel strength was estimated due to the absence of gelatin in the bagasse extract. However, the gelatin-free capsule shell has the advantage that it can be used by someone who is allergic to gelatin.

The elongation value was observed to have met the Japanese Industrial Standard (JIS) [14]which is required to be at a minimum elongation of $5 \%$ as indicated in Figure 6. This is due to the influence of the addition of glycerol as a plasticizer. The volume of glycerol being too high causes the distribution of the constituent components to be uneven [28]. This indicates more NCC content has the ability to increase the hydrogen bonds formed between the same polymers, thereby requiring more energy to break the bonds but having the ability to break them at low strains [27]. Moreover, the other NCC formulas have lower tensile strength values due to fewer hydrogen bonds, and this leads to weaker properties, easy deformation, and breakage at higher strains [7]. This was observed to be in line with the findings of Djafari Petroudy that the addition of more components of bagasse increased the tensile strength but reduced the elongation value [29]. The addition of HPMC was also observed to have increased the mechanical strength of the film.

The moisture content of all variations of NCC concentration was analyzed to determine the water content or humidity of the capsules [5], which is related to the resistance of the capsule shell to microbial activity, especially bacteria [30]. The moisture content required by the Japanese Industrial Standard (JIS) is $<10 \%$ [14], but those recorded in this study ranged from $6.15 \%$ to $9.5 \%$ as indicated in Figure 7 which is lower than the $12.5-15 \%$ in commercial capsule shells. This means all the variations of NCC have the 
TABLE 2: Functional group analysis of the CE and NCC.

\begin{tabular}{lccc}
\hline & & Wavenumber $\left(\mathrm{cm}^{-1}\right)$ & \\
$\mathrm{CE}$ & NCC & Range $\left(\mathrm{cm}^{-1}\right)$ & Functional group interpretation \\
\hline $3,443.05$ & $3,433.41$ & $34,00-3,200$ & O-H stretching vibration \\
$2,920.32$ & $2,860.53$ & $3,000-2,850$ & Sp3 C-H stretching \\
- & - & $1,750-1,735$ & $\mathrm{C}=\mathrm{O}$ stretching \\
$1,643.41$ & $1,635.69$ & $1,650-1,630$ & $\mathrm{OH}$ (air) \\
- & - & Around 1,600 and 1,475 & $\mathrm{C}$ aromatic ring \\
- & - & $1,600-1,500$ & $\mathrm{C}=\mathrm{C}$ aromatic ring \\
$1,371.43$ & $1,402.3$ & $1,440-1,000$ & $\mathrm{C}-\mathrm{O}-\mathrm{H}$ bending \\
$1,157.33$ & - & $1,300-1,000$ & $\mathrm{C}-\mathrm{O}$ stretching vibration \\
$1,066.67$ & $1,035.81$ & $1,300-1,000$ & $\mathrm{C}-\mathrm{O}$ stretching vibration \\
896.93 & - & Around 850 & Asymmetric C-O-C stretching vibration \\
- & - & $900-690$ & $=\mathrm{C}-\mathrm{H}$ stretching aromatic ring \\
\hline
\end{tabular}

TABLE 3: Physicochemical properties of nanocrystalline cellulose (NCC).

\begin{tabular}{lcc}
\hline Properties & & Sugarcane bagasse \\
& NCC $(1 \%, 2 \%, 4 \%$, and $7 \%)$ & Max 15\% \\
\hline Moisture (\%) & $6.15-9.50 \%$ & Max $5 \%$ \\
Ash (\%) & $2.50 \%$ & $6.5-8.5$ \\
pH value & $7.25-7.85$ & Min 0.3 \\
Gel strength (MPa) & $0.0529-0.1361$ & Min 5\% 5 \\
Elongation (\%) & $7.5-7.85 \%$ & \\
\hline
\end{tabular}

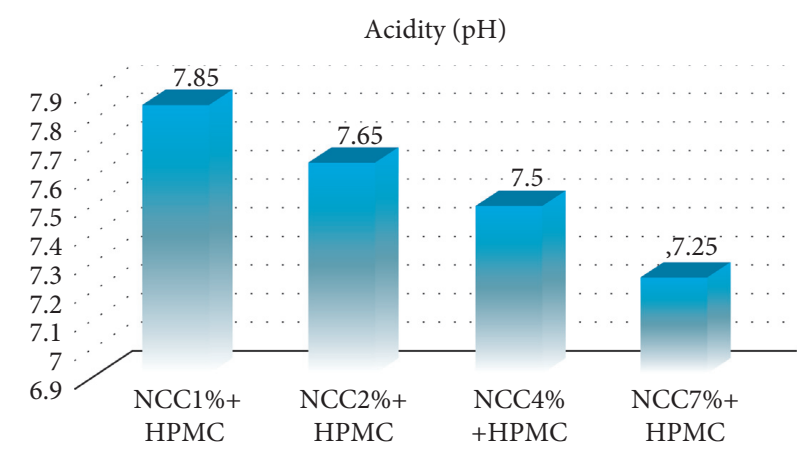

Figure 4: The pH value for $1 \%, 2 \%, 4 \%$, and $7 \%$ NCC with hydroxypropyl methylcellulose (HPMC).

TABLE 4: Gel strength results of the capsule shells from NCC produced from sugarcane bagasse waste added with hydroxypropyl methylcellulose (HPMC).

\begin{tabular}{|c|c|c|c|c|c|c|}
\hline \multirow{2}{*}{ Variation of NCC capsules with 1\% HPMC } & \multicolumn{2}{|c|}{ Gel strength $(\mathrm{MPa})$} & \multicolumn{2}{|c|}{ Elongation (\%) } & \multicolumn{2}{|c|}{ Moisture content (\%) } \\
\hline & Average & Standard deviation & Average & Standard deviation & Average & Standard deviation \\
\hline NCC $1 \%$ & 0.0765 & 0.0003 & 87.510 & 2.602 & 9.500 & 0.470 \\
\hline NCC $2 \%$ & 0.0529 & 0.0003 & 70.850 & 2.224 & 8.310 & 0.520 \\
\hline NCC $4 \%$ & 0.1008 & 0.0002 & 11.880 & 2.067 & 6.150 & 0.679 \\
\hline NCC $7 \%$ & 0.1361 & 0.0001 & 7.190 & 0.430 & 8.740 & 0.580 \\
\hline
\end{tabular}

required water content and have the potential to be better in terms of storage as containers for drugs are considered to be sensitive to moisture and are not easily overgrown with microbes, thereby extending the shelf life of the capsule [31].

3.4. Capsule Shell. Nanocrystalline cellulose (NCC) capsules were produced at $1 \%, 2 \%, 4 \%$, and $7 \%$ concentration. It is important to note that the capsule forming device affected the shape of the capsule, as indicated in Figure 8. The preliminary formulation of the NCC concentration was in the form of a film, but the results showed that the film was not formed but rather returned to form a colloid because the viscosity was too low. This led to the addition of HPMC to increase the flexibility and allow it to be printed on the capsule printer [21]. The HPMC additives were selected due to their proven compatibility with NCC [32].

The HPMC concentration used was $1 \%$, and this allowed $1 \%, 2 \%, 4 \%$, and $7 \%$ NCC concentrations to be printed on the capsule printer. It is also important to note that $1 \%$ 


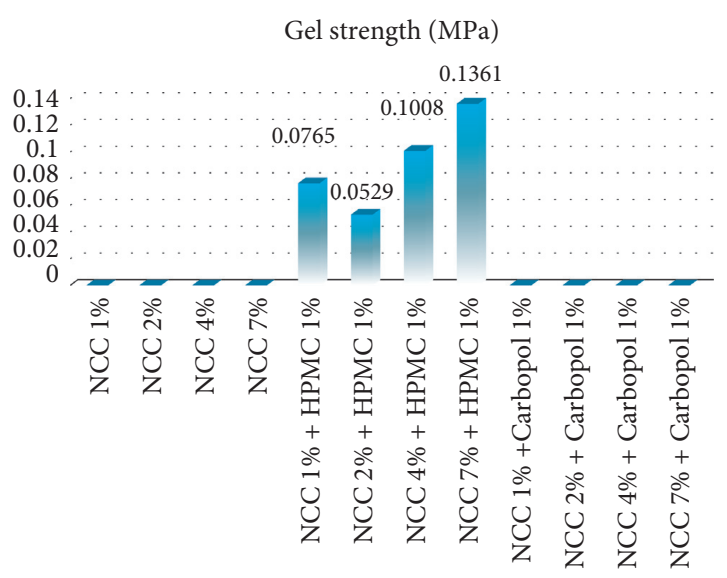

FIgURE 5: The gel strength (MPa) values for $1 \%, 2 \%, 4 \%$, and $7 \%$ NCC with hydroxypropyl methylcellulose (HPMC) and carbopol

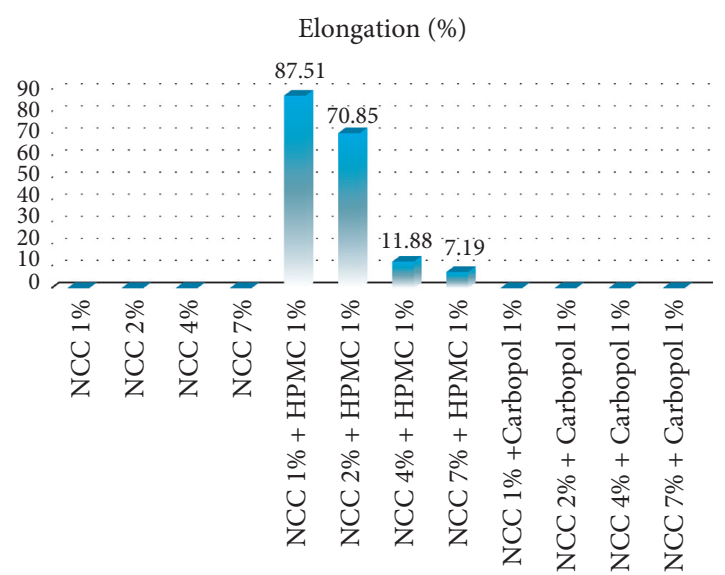

Figure 6: The elongation (\%) values for 1\%, 2\%, 4\%, and 7\% NCC with hydroxypropyl methylcellulose (HPMC) and carbopol.

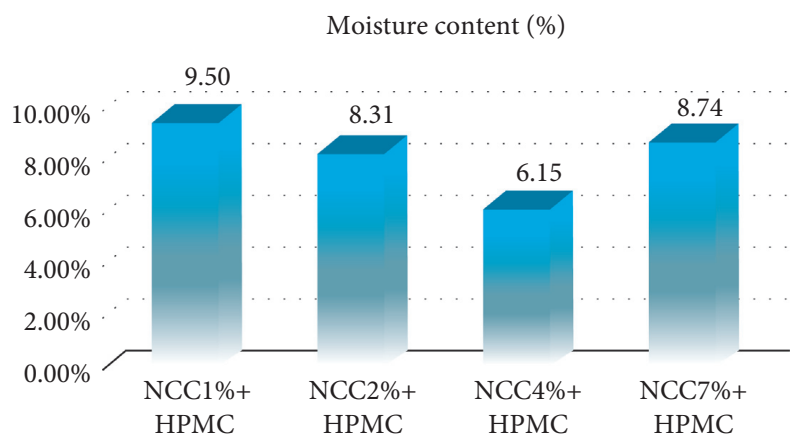

Figure 7: The moisture content (\%) value for $1 \%, 2 \%, 4 \%$, and $7 \%$ NCC with hydroxypropyl methylcellulose (HPMC).

carbopol was also added, and this material was selected due to its easy dispersion in water at a small concentration of $0.05-2 \%$, but it has a very high viscosity which limits its ability to form a film. PEG-400 and glycerin were also added as plasticizers to reduce the stiffness of the polymer and increase the flexibility of the capsule shell produced [17]. The decrease in the polymer strength was caused by the reduction in the internal hydrogen bonds of the

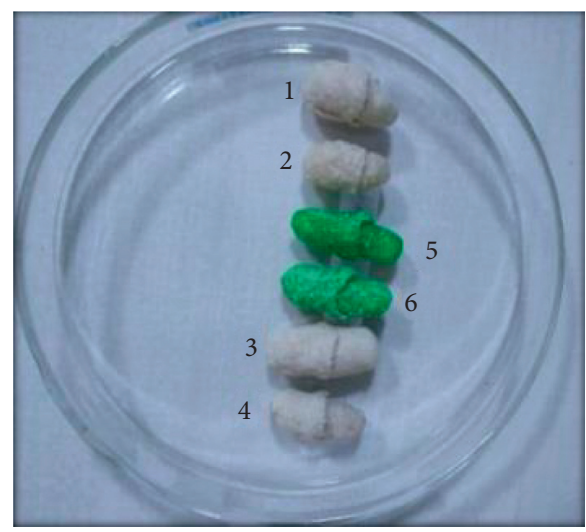

FIgURE 8: Capsule shells produced from the NCC of sugarcane bagasse waste mixed with hydroxypropyl methylcellulose (HPMC) and carbopol. (1) Capsules were produced at $1 \%$ NCC concentration $+1 \%$ HPMC; (2) capsules were produced at $2 \%$ NCC concentration $+1 \%$ HPMC; (3) capsules were produced at $4 \%$ NCC concentration $+1 \%$ HPMC; (4) capsules were produced at $7 \%$ NCC concentration $+1 \%$ HPMC; (5) capsules were produced at $4 \%$ NCC concentration $+1 \%$ carbopol; and (6) capsules were produced at $7 \%$ NCC concentration $+1 \%$ carbopol.

intermolecular bonds [33]. Meanwhile, the PEG-400 was selected due to its ability to absorb moisture from the capsule shell [10] and was used at a $2 \%$ concentration, which is within the $<30 \%$ allowed for parenteral preparations.

The solubility of nanocrystalline cellulose (NCC) was tested using three solvents, which included distilled water, acetone, and n-hexane at different polarity levels of polar, semipolar, and nonpolar. The results showed that the NCC can be dispersed in distilled water but not in acetone and $\mathrm{n}$-hexane. This is in accordance with the Japanese Industrial Standard (JIS) [14] that NCC is easily dispersed in water and forms a colloidal solution but is insoluble in acetone and n-hexane.

3.5. Capsule Disintegration Test. The capsule disintegration was tested to determine the time for the capsules to disintegrate, and the results are presented in Table 5. This is necessary because the capsule needs to decompose within a certain period for the ingredients encapsulated to be absorbed by the body [10-12]. The test was conducted on Milli-Q water medium at a temperature of $37^{\circ} \mathrm{C} \pm 2{ }^{\circ} \mathrm{C}$, which is adapted to human body temperature and a total of 6 capsule shells were used [8] at 1\%, 2\%, 4\%, and 7\% NCC with $1 \%$ HPMC. The results showed the capsule shell required 30 minutes to disintegrate.

Research on making capsules using bagasse which is synthesized into a form of nanocrystalline cellulose (NCC) was analyzed with several test parameters to obtain the optimal concentration of NCC in the manufacture of capsules. The values of gel strength (Table 4), elongation (Figure 7), and disintegration test results (Table 5) show that the higher the concentration of NCC with the addition of HPMC, the higher the values of gel strength and disintegration tests will be, but higher NCC concentrations have lower elongation values. The gel strength is lower than the 
TABLE 5: Disintegration test results of the capsule shells from NCC produced from sugarcane bagasse waste added with hydroxypropyl methylcellulose (HPMC) and carbopol.

\begin{tabular}{lcccccccc}
\hline \multirow{2}{*}{ Variation of NCC capsules with HPMC } & \multicolumn{9}{c}{ Disintegration time (minutes) } & \multirow{2}{*}{ Average time (minutes) } & \multirow{2}{*}{ Standard deviation } \\
& S1 & S2 & S3 & S4 & S5 & S6 & & 1.23 \\
NCC 1\% & 7.32 & 5.53 & 5.57 & 8.12 & 6.18 & 8.24 & 6.82 & 3.61 \\
NCC 2\% & 3.00 & 4.21 & 4.33 & 3.55 & 2.14 & 4.46 & 4.97 & 2.59 \\
NCC 4\% & 4.30 & 4.24 & 3.54 & 10.23 & 4.08 & 3.46 & 9.03 & 1.09 \\
NCC 7\% & 9.27 & 8.56 & 7.59 & 10.23 & 8.23 & 10.36 & & 9 \\
\hline
\end{tabular}

$\mathrm{S}=$ sample.

Japanese Industrial Standard (JIS) [14] because bagasse is a gelatin-free capsule shell material.

\section{Conclusion}

The sample with the lowest water content is $4 \%$ NCC, and this indicates it has better potential to serve as a drug container due to the fact that it cannot be easily overgrown by microbes, thereby prolonging the shelf life of the capsule. Moreover, the sample with the highest tensile strength is 7\% NCC at $0.1361 \mathrm{MPa}$, but the value is below the $0.3 \mathrm{MPa}$ required by the Japanese industrial standard (JIS), while the highest elongation of $87.51 \%$ was recorded in $1 \%$ NCC, which is significantly higher than the required minimum of $5 \%$. The $\mathrm{pH}$ for all the variations was discovered to be between 6.5 and 8.5, and this implies the NCC is safe to use as raw material to produce capsule shells. Therefore, the optimum concentration of nanocrystalline cellulose (NCC) to manufacture capsules is $4 \%$ in combination with HPMC.

\section{Data Availability}

The data used to support the findings of this study are available from the corresponding author upon request.

\section{Conflicts of Interest}

The authors declare that there are no conflicts of interest regarding the publication of this article and confirmed that the data and paper are free of plagiarism.

\section{References}

[1] J. A. Adebisi, J. O. Agunsoye, S. A. Bello et al., "Extraction of silica from sugarcane bagasse, cassava periderm and maize stalk: proximate analysis and physico-chemical properties of wastes," Waste and Biomass Valorization, vol. 10, no. 3, pp. 617-629, 2019.

[2] T. Sriyakul, R. Umam, and K. Jermsittiparsert, "Total quality management and logistic performance: moderating role of reserve supply chain in pharmaceutical industry of Indonesia," International Journal of Innovation, Creativity and Change, vol. 5, no. 2, pp. 228-248, 2019.

[3] A. Abdurrahman, R. Umam, I. Irzaman et al., "Optimization and interpretation of heat distribution in sterilization room using convection pipe," Indonesian Journal of Science and Technology, vol. 4, no. 2, pp. 204-219, 2019.

[4] B. Kurniawan, W. Rudiyanto, H. Mutiara, A. Stefani, R. Umam, and K. Jermsittiparsert, "Correlation between parasitemia with hemoglobin levels in malaria patients at
Hanura health center working area Pesawaran district, Lampung, Indonesia," Systematic Reviews in Pharmacy, vol. 10, no. 2, pp. 297-302, 2019.

[5] L. J. R. Nunes, L. M. E. F. Loureiro, L. C. R. Sá, and H. F. C. Silva, "Sugarcane industry waste recovery: a case study using thermochemical conversion technologies to increase sustainability," Applied Sciences, vol. 10, no. 18, pp. 6481-18, 2020.

[6] R. Umam and K. Sommanawat, "Strategic flexibility, manufacturing flexibility, and firm performance under the presence of an agile supply chain: a case of strategic management in fashion industry," Polish Journal of Management Studies, vol. 19, no. 2, pp. 407-418, 2019.

[7] R. B. Dagadiye, A. D. Kajale, V. K. Mahajan, and M. H. Joshi, "Advancement in manufacturing of non-gelatin capsule shella review," International Journal of Advances in Pharmaceutical Research, vol. 3, no. 10, pp. 1178-1187, 2012.

[8] M. Nurilmala, H. Suryamarevita, H. Husein Hizbullah, A. M. Jacoeb, and Y. Ochiai, "Fish skin as a biomaterial for halal collagen and gelatin," Saudi Journal of Biological Sciences, vol. 29, no. 2, pp. 1100-1110, 2021.

[9] B. Kurniawan, L. Puspita, Y. Kurnia et al., "Utilization of stem bark and leaves of Kluwih (Artocarpus altilis park) as an antimosquito repellent: a case study of total mosquito mortality (anopheles sp)," Indonesian Journal of Science and Technology, vol. 5, no. 3, pp. 421-439, 2020.

[10] J. A. C. Barbosa, M. M. Al-Kauraishi, A. M. Smith, B. R. Conway, and H. A. Merchant, "Achieving gastroresistance without coating: formulation of capsule shells from enteric polymers," European Journal of Pharmaceutics and Biopharmaceutics, vol. 144, pp. 174-179, 2019.

[11] M. M. Al-Tabakha, "HPMC capsules: current status and future prospects," Journal of Pharmacy \& Pharmaceutical Sciences, vol. 13, no. 3, pp. 428-442, 2010.

[12] E. K. Haque, K. Kanemitsu, and Y. Tsuda, "Synthesis of some deoxy, unsaturated, and dideoxy sugars via regioselective thioacylation of glycopyranosides by the dibutyltin oxide method," Chemical and Pharmaceutical Bulletin, vol. 34, no. 1, pp. 430-433, 1986.

[13] E. Rufaidaha, K. A. AtIrsyadib, A. Saregar, and R. Umam, "The effect of HALAL label to increase domestic and international tourism: case study in Lombok, Indonesia," International Journal of Management and Business Research, vol. 8, no. 4, pp. 29-36, 2018.

[14] T. C. Morphology, Japanese Industrial StandardJapanese Industrial Standard, Tokyo, Japan, 2017.

[15] Z. Sabara, A. Anwar, S. Yani et al., "Activated carbon and coconut coir with the incorporation of ABR system as greywater filter: the implications for wastewater treatment," Sustainability, vol. 14, no. 2, Article ID 1026, 2022.

[16] S. Nikmatin, B. Hermawan, Irmansyah, M. N. Indro, M. D. Sukardan, and R. Umam, "Kinematics and dynamics of the ballistic impact behavior for an oil palm empty fruit bunch 
fiber reinforced bio-composite," Bioresources, vol. 15, no. 3, pp. 6123-6134, 2020.

[17] R. Caillard, J.-S. Blais, G. Akinocho, and W. Jacques, "Characterization of a food-based enteric coating for capsules and its compatibility with an alternative sealing method," International Journal of Pharmaceutics, vol. 499, no. 1-2, pp. 321-329, 2016.

[18] N. Sato-Masumoto, S. Masada, S. Takahashi et al., "Disintegration test of health food products containing Ginkgo biloba L. or Vitex agnus-castus L. in the Japanese market," Medicines, vol. 2, no. 2, pp. 47-54, 2015.

[19] D. A. Silva, G. K. Webster, N. Bou-Chacra, and R. Löbenberg, "The significance of disintegration testing in pharmaceutical development," Dissolution Technologies, vol. 25, no. 3, pp. $30-38,2018$.

[20] J. Al-Gousous and P. Langguth, "Oral solid dosage form disintegration testing-the forgotten test," Journal of Pharmaceutical Sciences, vol. 104, no. 9, pp. 2664-2675, 2015.

[21] E. Macchi, L. Zema, P. Pandey, A. Gazzaniga, and L. A. Felton, "Influence of temperature and relative humidity conditions on the pan coating of hydroxypropyl cellulose molded capsules," European Journal of Pharmaceutics and Biopharmaceutics, vol. 100, pp. 47-57, 2016.

[22] E. K. Palupi, R. Umam, B. B. Andriana et al., "Micro-Raman analysis of $\mathrm{Ba}_{0.2} \mathrm{Sr}_{0.8} \mathrm{TiO}_{3}$ (barium strontium titanate) doped of chlorophyll of cassava leaf," Ferroelectrics, vol. 540, no. 1, pp. 227-237, 2019.

[23] D. Ariyanti and K. Megasari, "Determining optical band gap energy of chitosan biopolymer film as the effect of gamma rays irradiation," Jurnal Ilmiah Pendidikan Fisika Al-Biruni, vol. 10, no. 1, pp. 129-138, 2021.

[24] B. Astuti, P. Marwoto, A. Zhafirah et al., "Structure, morphology, and optical properties of $\mathrm{ZnO}: \mathrm{Mg}$ thin film prepared by sol-gel spin coating method," Jurnal Ilmiah Pendidikan Fisika Al-Biruni, vol. 10, no. 2, pp. 241-250, 2021.

[25] M. I. Said, Y. Erwanto, A. Fudholi, and E. Abustam, "Development of prototype of hard capsule shell made from goatskin gelatin using simplex lattice design (SLD) as optimization method," Buletin Peternakan, vol. 42, no. 4, pp. 327-333, 2018.

[26] S. Yamashita, K. Iguchi, Y. Noguchi et al., "Changes in the quality of medicines during storage under LED lighting and consideration of countermeasures," Journal of Pharmaceutical Health Care and Sciences, vol. 4, no. 1, pp. 1-6, 2018.

[27] M. Nurilmala, N. Darmawan, E. A. W. Putri, A. M. Jacoeb, and T. T. Irawadi, "Pangasius fish skin and swim bladder as gelatin sources for hard capsule material," International Journal of Biomaterials, vol. 2021, Article ID 6658002, 6 pages, 2021.

[28] F. Damian, M. Harati, J. Schwartzenhauer, O. Van Cauwenberghe, and S. D. Wettig, "Challenges of dissolution methods development for soft gelatin capsules," Pharmaceutics, vol. 13, no. 2, pp. 214-230, 2021.

[29] S. R. Djafari Petroudy, "Advanced high strength natural fibre composites in construction," in Physical and Mechanical Properties of Natural Fibers, pp. 59-83, Elsevier BV, Amsterdam, Netherlands, 2017.

[30] N. L. L. Amie and A. Nugraha, "Pemanfaatanlimbah ampas tebu melalui desain produk perlengkapan rumah," Tingkat Sarjana Senirupa dan Desain, vol. 1, pp. 1-7, 2014.

[31] T. Hakata, H. Sato, Y. Watanabe, and M. Matsumoto, "Effect of formaldehyde on the physicochemical properties of soft gelatin capsule shells," Chemical and Pharmaceutical Bulletin, vol. 42, no. 5, pp. 1138-1142, 1994.
[32] Y. Yang, L. Shen, F. Yuan, H. Fu, and W. Shan, "Preparation of sustained release capsules by electrostatic dry powder coating, using traditional dip coating as reference," International Journal of Pharmaceutics, vol. 543, no. 1-2, pp. 345-351, 2018.

[33] N. Reix, P. Guhmann, W. Bietiger, M. Pinget, N. Jeandidier, and S. Sigrist, "Duodenum-specific drug delivery: in vivo assessment of a pharmaceutically developed enteric-coated capsule for a broad applicability in rat studies," International Journal of Pharmaceutics, vol. 422, no. 1-2, pp. 338-340, 2012. 